\title{
Volcano impacts on climate and biogeochemistry in a coupled carbon-climate model
}

\author{
D. Rothenberg ${ }^{1, *}$, N. Mahowald ${ }^{1}$, K. Lindsay ${ }^{2}$, S. C. Doney ${ }^{3}$, J. K. Moore ${ }^{4}$, and P. Thornton ${ }^{5}$ \\ ${ }^{1}$ Department of Earth and Atmospheric Sciences, Cornell University, Ithaca, NY 14853, USA \\ ${ }^{2}$ Climate and Global Dynamics Division, National Center for Atmospheric Research, Boulder, CO 80305, USA \\ ${ }^{3}$ Department of Marine Chemistry and Geochemistry, Woods Hole Oceanographic Institution, Woods Hole, MA 02543, USA \\ ${ }^{4}$ Department of Earth System Science, University of California, Irvine, CA 92697, USA \\ ${ }^{5}$ Environmental Sciences Division, Oak Ridge National Laboratory, Oak Ridge, TN 37831, USA \\ * now at: Department of Earth, Atmospheric, and Planetary Sciences, Massachusetts Institute of Technology, \\ Cambridge, MA 02139, USA
}

Correspondence to: D. Rothenberg (darothen@mit.edu)

Received: 21 March 2012 - Published in Earth Syst. Dynam. Discuss.: 18 April 2012

Revised: 7 September 2012 - Accepted: 11 September 2012 - Published: 19 October 2012

\begin{abstract}
Volcanic eruptions induce a dynamical response in the climate system characterized by short-term global reductions in both surface temperature and precipitation, as well as a response in biogeochemistry. The available observations of these responses to volcanic eruptions, such as to Pinatubo, provide a valuable method to compare against model simulations. Here, the Community Climate System Model Version 3 (CCSM3) reproduces the physical climate response to volcanic eruptions in a realistic way, as compared to direct observations from the 1991 eruption of Mount Pinatubo. The model's biogeochemical response to eruptions is smaller in magnitude than observed, but because of the lack of observations, it is not clear why or where the modeled carbon response is not strong enough. Comparison to other models suggests that this model response is much weaker over tropical land; however, the precipitation response in other models is not accurate, suggesting that other models could be getting the right response for the wrong reason. The underestimated carbon response in the model compared to observations could also be due to the ash and lava input of biogeochemically important species to the ocean, which are not included in the simulation. A statistically significant reduction in the simulated carbon dioxide growth rate is seen at the $90 \%$ level in the average of 12 large eruptions over the period 1870-2000, and the net uptake of carbon is primarily concentrated in the tropics, with large spatial variability. In addition, a method for computing the volcanic response
\end{abstract}

in model output without using a control ensemble is tested against a traditional methodology using two separate ensembles of runs; the method is found to produce similar results in the global average. These results suggest that not only is simulating volcanoes a good test of coupled carbon-climate models, but also that this test can be performed without a control simulation in cases where it is not practical to run separate ensembles with and without volcanic eruptions.

\section{Introduction}

Volcanic eruptions provide sharp, transient, and relatively well-understood forcings to the climate system, and induce short-term global surface cooling and lower-stratospheric warming in their aftermath (Mass and Portman, 1989; Robock and Mao, 1992, 1995; Shindell et al., 2004). This response is due to the eruptions' injection of large amounts of sulfate aerosols into the stratosphere, which increases the amount of incoming solar radiation reflected back out to space at the top of the atmosphere. Although stratospheric aerosols tend to mix relatively quickly in the atmosphere (less than a few months), tropical eruptions tend to have greater climate impacts than high-latitude ones, due to both longer residence times of their aerosols as well as an apparent stronger dynamic response (Oman et al., 2005). 
The forcing from volcanic eruptions tends to cool the tropics but produces some continental warming in the winter, similar in spatial pattern to a shift towards the positive phase of the Arctic Oscillation in the Northern Hemisphere (Stenchikov et al., 2006; Oman et al., 2005; Shindell et al., 2004). It has also been observed in the paleoclimate record that a multi-year, El Niño-like response can be induced in the atmosphere-ocean system as a response to explosive tropical volcanic eruptions (Adams et al., 2003).

Because of their strong impacts on climate, volcanic eruptions provide good natural experiments to test the sensitivity of climate models. Very large volcanic explosions appear to increase the likelihood of an El Niño event (Emile-Geay et al., 2008). Stenchikov et al. (2006) analyzed the IPCC AR4 climate models and showed that although the included models reproduced a post-eruption shift to the positive phase of the Arctic Oscillation, there was considerable spread in the set of the models' particular dynamic responses. Furthermore, the winter warming of the continents in the Northern Hemisphere (associated with a shift to the positive phase of the AO) was much weaker in the models than in the observational record (Stenchikov et al., 2006). The models analyzed by Stenchikov et al. (2006) also failed to show a preference for El Niño conditions following eruptions, contrary to the response identified by Adams et al. (2003) in the paleoclimate record.

Direct observations of the 1991 Mount Pinatubo eruption provide a baseline for analyzing the models' physical climate responses to volcanoes. While the Pinatubo eruption produced global surface cooling of about $0.5^{\circ} \mathrm{C}$ (Hansen et al., 1996), it yielded strong continental warming in the Northern Hemisphere winter following the eruption (Shindell et al., 2004). Precipitation over land was strongly diminished in the aftermath of Pinatubo as well, especially in Europe and in the tropics in South America and Africa (Trenberth and Dai, 2007).

The surface cooling, increase in diffuse radiation, and global precipitation reduction following eruptions have impacts on the carbon cycle. In 1991, the growth rate of atmospheric $\mathrm{CO}_{2}$ was expected to rise due to the onset of El Niño, but in the aftermath of the Pinatubo eruption, the growth rate slowed for several years (Sarmiento, 1993). This Pinatubo- $\mathrm{CO}_{2}$ anomaly was potentially linked to a connection between post-eruption global cooling and a resulting shift in the behavior of the terrestrial biosphere. However, it is difficult to directly ascribe variability in atmospheric $\mathrm{CO}_{2}$ to volcanic eruptions because inter-annual variability in atmospheric $\mathrm{CO}_{2}$ is closely tied to the El Niño-Southern Oscillation (ENSO) (Jones et al., 2001). During periods of El Niño, the terrestrial biosphere becomes a net source of $\mathrm{CO}_{2}$ to the atmosphere, whereas the opposite trend occurs during La Niña events (Jones et al., 2001); thus, deconvolving the effects of volcanoes from El Niño events is difficult. Observational evidence is too limited to diagnose from observations what is driving the carbon response. Tree ring records suggest that in some temperate forests, net primary production is reduced due to volcano-induced cooling (Krakauer and Randerson, 2003). A transient reduction in net primary production in the high latitudes following Pinatubo has been attributed to decreased growing-season length due to volcanic-induced cooling (Nemani et al., 2003). However, some low-latitude ecosystems experienced increased plant growth as cooling reduced evaporative demand or volcanic ash increased diffuse radiation (Nemani et al., 2003). Enhanced uptake of carbon over North America during 19921993, as compared to previous time periods, has also been observed (Bousquet et al., 2000).

The ocean response to volcanoes is not well documented. Some authors argue that the additional nutrients and trace elements added to the ocean may be responsible for additional carbon uptake (e.g., Watson, 1997; Frogner et al., 2001; Duggen et al., 2007, 2010), but a quantitative assessment of this effect on global carbon or ocean productivity has not yet been performed. The strength at which land and ocean sinks reduce atmospheric $\mathrm{CO}_{2}$ is not increasing at the same rate as anthropogenic emissions are increasing (Le Quéré et al., 2009; Sarmiento et al., 2010), as evidenced by an increase in atmospheric $\mathrm{CO}_{2}$ levels. Modeling studies suggest that the balance of increased carbon uptake associated with $\mathrm{CO}_{2}$ fertilization and decreased uptake associated with global warming could lead to a reduction in the efficiency of the land sink of carbon in the future (Cox et al., 2000; Friedlingstein et al., 2006; Thornton et al., 2009; Sitch et al., 2008). Studies of future carbon dioxide levels tend to use sophisticated coupled carbon cycle models, and one of the difficulties with these models is finding ways to test their response to climate change. The carbon cycle response to volcanoes is a valuable testing metric (Jones and Cox, 2001; Friedlingstein and Prentice, 2010).

This study investigates the performance of one coupled carbon-climate model - the CCSM3 (Thornton et al., 2009; Mahowald et al., 2011) - by analyzing the responses by the ocean and land carbon cycle to volcanic eruptions during the period 1870-2000. This study differs from previous studies in several ways: It looks at multiple volcanoes over $130 \mathrm{yr}$, while Jones and Cox (2001) focused on the volcanic forcing of climate and the impact on the carbon cycle using a different model and only for the Pinatubo eruption, and Brovkin et al. (2010) looked at the role of eruptions over the last $1000 \mathrm{yr}$. In addition, this study compares the response using a control case (without volcanoes) to an analysis without a control case. This additional analysis allows us to consider to what extent we can diagnose the response of volcanoes in transient simulations where there was not a paired control simulation that did not include eruptions. It also indicates what fraction of the true volcano signal we expect to see in the real world, where we have no control case. Previous studies at higher resolution with the CCSM3 suggest that the model is able to capture the observed response to volcanoes (Schneider et al., 2009), but generally has difficulty in 
accurately capturing El Niño (Deser et al., 2006). This paper, similar to Jones and Cox (2001), does not consider the potentially important impacts of the addition of biogeochemically relevant species from a volcanic eruption, but only the response to the physical forcing. Section 2 describes the model configuration and experimental setup for the simulations in these studies. Section 3 describes the results, and Sect. 4 summarizes and discusses the implications of this study.

\section{Methods}

\subsection{Model description}

The model used here is based on the NCAR Community Climate System Model Version 3 (CCSM3) as described in Collins et al. (2006a) and Yeager et al. (2006) and is run in a coupled configuration with atmosphere, land, ocean, and sea ice components with the addition of a fully-coupled carbon cycle with land and ocean components, as described in Thornton et al. (2009) and Mahowald et al. (2011). The model was configured identically to the one used in the aerosol experiments in Mahowald et al. (2011), with the CAM atmosphere model component running at a T31 resolution $\left(3.75^{\circ} \times 3.75^{\circ}\right.$ latitude by longitude grid) with 26 vertical levels (Collins et al., 2006b); it included estimates of historical volcanic forcing, as well as prognostic carbonaceous, sulfate, dust and sea salt aerosols and corresponding emissions varying over the time period 1870-2000 (Meehl et al., 2006). The time-varying volcanic forcing dataset (prescribing volcanic aerosol loading) used here, as well as in Meehl et al. (2006), is derived from previous work by Ammann et al. (2003).

Ammann et al. (2003) scaled the peak aerosol depth for 20th century eruptions by looking at previous estimates of peak aerosol loading, and assumed a consistent composition of $75 \% \mathrm{H}_{2} \mathrm{SO}_{4}$ and $25 \% \mathrm{H}_{2} \mathrm{O}$ and fixed aerosol size distribution (with $r_{\mathrm{eff}}=0.42$ micron). This is comparable to the composition of Pinatubo's aerosols (Ammann et al., 2003). Immediately following the month of the eruption, the aerosols build up linearly in the lower stratosphere (150 to $50 \mathrm{hPa}$ ) for four months before reaching the estimated peak load of sulfate aerosol. In the forcing dataset, volcanic aerosols are removed at the poles during winter, and the e-folding time for their decay in the tropics is 12 months (Ammann et al., 2003). The enhanced loading of stratospheric volcanic aerosols tends to increase the diffuse radiation fraction until the aerosols are removed. Ammann et al. (2003) suggest that their parameterization for the post-eruption atmospheric aerosol loading successfully reproduces the timing and hemispheric evolution of aerosol spread except for the eruptions of Agung in 1963 and El Chichón in 1982. Following the Agung eruption, the model used by Ammann et al. (2003) overestimated the amount of aerosol transported to the Northern Hemisphere, whereas following the eruption of
El Chichón, more aerosols were observed in the Northern Hemisphere than the model predicted.

The land carbon cycle used in these simulations (CLM$\mathrm{CN}$ ) includes linked carbon and nitrogen cycles (Thornton et al., 2007). The land biogeochemistry in this model includes $\mathrm{N}$ limitation, which reduces carbon uptake in the presence of higher $\mathrm{CO}_{2}$ conditions (Thornton et al., 2007). Gross primary production increases with larger diffuse radiation fraction in the model (Thornton and Zimmermann, 2007). The CLM-CN has been previously evaluated for its mean behavior by Randerson et al. (2009). Ocean biogeochemistry is handled here with the Biogeochemical Element Cycling (BEC) model (Moore et al., 2004), which includes a full depth carbon cycle module, and has been compared against available observations by Doney et al. (2009a,b). The BEC model also features several phytoplankton functional groups (including diazotrophs, diatoms, and smaller phytoplankton) and growth-limiting nutrients (nitrate, phosphate, iron, and others) (Thornton et al., 2009).

The CCSM3 also includes a module modeling sources, atmospheric transport, and deposition of desert dust, as described by Zender et al. (2003) and Mahowald et al. (2006). The dust model generates dust in regions with unvegetated, dry soils with strong winds and easily erodible soil (Zender et al., 2003). Interactions between the dust and ocean biogeochemistry modules has previously been investigated (Mahowald et al., 2011). Changes in dust deposition affect ocean productivity by perturbing iron limitation of nitrogen fixing organisms and ultimately impacts oceanic uptake of carbon dioxide in the model.

\section{Ensemble member setup}

Model runs were branched from a control run after $50 \mathrm{yr}$ and subsequently integrated over a 130 -yr period spanning 1870-2000, as described in more detail in Mahowald et al. (2011). In addition to the "AEROSOL" simulation referred to in that paper, two additional ensemble members with volcanoes were set up and integrated for this study, branched from points set ten years apart. Another ensemble of three branched simulations was computed here, but with volcanoes disabled for the entire period of integration (control simulations).

\subsection{Volcanic eruptions}

A selection of eruptions (see Table 1) was made based on Robock and Mao (1992), and adjusted to facilitate comparison to other papers by choosing only the most commonly analyzed eruptions (Jones and Cox, 2001; Robock and Liu, 1994; Shindell et al., 2004; Oman et al., 2005; Stenchikov et al., 2006; Schneider et al., 2009). Robock and Mao (1992) chose eruptions (Table 1) occurring between 1870-2000 that satisfied the criteria of VEI (volcanic explosivity index) $\geq 5$ or DVI (dust veil index) $\geq 250$. These criteria were chosen 
Table 1. Years of selected volcanic eruptions modified from Robock and Mao (1992). DVI denotes "Dust Veil Index", and VEI denotes "Volcanic Explosivity Index".

\begin{tabular}{lrrcc}
\hline Volcano & $\begin{array}{c}\text { Eruption } \\
\text { Year }\end{array}$ & Lat. & DVI & VEI \\
\hline Krakata** & 1883 & $6^{\circ} \mathrm{S}$ & 1000 & 6 \\
Tarawera & 1886 & $38^{\circ} \mathrm{S}$ & 800 & 5 \\
Bandai & 1888 & $38^{\circ} \mathrm{N}$ & 500 & 4 \\
Santa Maria* & 1902 & $15^{\circ} \mathrm{S}$ & 600 & 6 \\
Ksudach & 1907 & $52^{\circ} \mathrm{N}$ & 500 & 5 \\
Katmai & 1912 & $58^{\circ} \mathrm{N}$ & 500 & 6 \\
Quizapu & 1932 & $36^{\circ} \mathrm{S}$ & 70 & 5 \\
Bezymianny & 1956 & $56^{\circ} \mathrm{N}$ & 30 & 5 \\
Agung* & 1963 & $8^{\circ} \mathrm{S}$ & 800 & 4 \\
Fuego & 1974 & $14^{\circ} \mathrm{N}$ & 250 & 4 \\
El Chichón* & 1982 & $17^{\circ} \mathrm{N}$ & 800 & 5 \\
Mt. Pinatubo* & 1991 & $15^{\circ} \mathrm{N}$ & 1000 & 6 \\
\hline
\end{tabular}

* Denotes eruption was used for the analyses presented here, except where otherwise indicated.

to maximize the potential climate impacts of each eruption; large VEIs correspond to eruptions emitting a large volume of tephra in a tall eruption cloud, and large DVIs are associated with a large release of dust and aerosols that impact the Earth's radiative balance during the years immediately following an eruption. The combination of high VEI and DVI help to maximize a volcano's impact on Earth's energy balance, yielding a more visible signal in the climate record (via short-term surface cooling). The analyses presented in this study were performed with the subset of these eruptions indicated in Table 1. Because the eruptions compiled by Robock and Mao (1992) contain a mixture of highand low-latitude eruptions and eruptions occurring in various seasons, the response to eruptions tends to be averaged out when all the eruptions are included in the analysis performed here. The subset of five eruptions - Krakatau, Santa Maria, Agung, El Chichón, and Pinatubo - was chosen by taking the largest tropical eruptions which yielded the most significant physical climate response.

\subsection{Model and data analysis}

\subsubsection{Time series}

Trends in the climate record immediately following volcanic eruptions were computed by analyzing time series of anomalies between paired ensemble members - one which included volcanoes and a matched control. Four-year time series were composited starting at the month of each eruption for each model run in the two ensembles; the time series were separated into a group with eruptions and a control without. For each month, the mean and standard deviation for the difference between the eruption and control samples was computed. This mean anomaly between volcanic runs and control runs was compared to the set of anomaly time series for each individual eruption, averaged over the three pairs (volcano-control) of ensemble members. Comparing the set of anomaly time series to the mean for each individual eruption facilitates the study of the range of responses to volcanoes at different latitudes and with different explosive indices (Table 1).

In addition, a second anomaly was computed without making reference to the control simulations ("no-control" case) by analyzing deviations from the average seasonal cycle immediately preceding each eruption. For each month in the years following the eruption, an anomaly is computed based on the two years prior to the eruption, computing the deviation from the average seasonal cycle. The results are not sensitive to changing the time period of the averaging beforehand (not shown here). To compute the 'no-control' anomaly for atmospheric $\mathrm{CO}_{2}$ following Pinatubo, a similar procedure was used, but the data was detrended before computing the seasonal cycle to facilitate comparisons between the data before and after the eruption; in order to detrend the data, a linear regression was performed on a 20 -yr period centered at the eruption and subtracted from the simulation time series.

\subsubsection{Pinatubo}

Jones et al. (2001) performed an ensemble of 9 runs with the HadCM3 over the time period 1990 to 1996 to investigate the effect of the Pinatubo eruption on the dynamics of the climate and biogeochemistry. They compared surface temperature observations to model-computed temperatures, and analyzed the components of the model contributing to the terrestrial biosphere's uptake of $\mathrm{CO}_{2}$ over the duration of the model runs. Similar analyses were performed here to compare the CCSM3's performance to the HadCM3 by analyzing the ensemble of 3 paired runs over equivalent time periods and computing both the "volcano-control" and "nocontrol" anomalies as previously described.

\subsubsection{Global analyses}

To analyze spatial patterns in the response to volcanic eruptions, seasonally-averaged anomalies were computed using each of the methods described in the previous section at each latitude-longitude grid point by taking the average anomaly for each individual eruption and averaging them all over the subset of five eruptions. For the "volcano-control" anomalies, statistical significance was computed by performing a Student's $t$-test to test whether the mean difference between the set of volcano data and control data at a given grid point over the time period being averaged was different at a significance level of $90 \%$. For the "no-control" anomalies, a onesample Student's $t$-test was used to test whether the mean of the anomalies was significantly different from 0 at a significance level of $90 \%$. Only statistically significant anomalies are plotted in the figures detailing these analyses. 

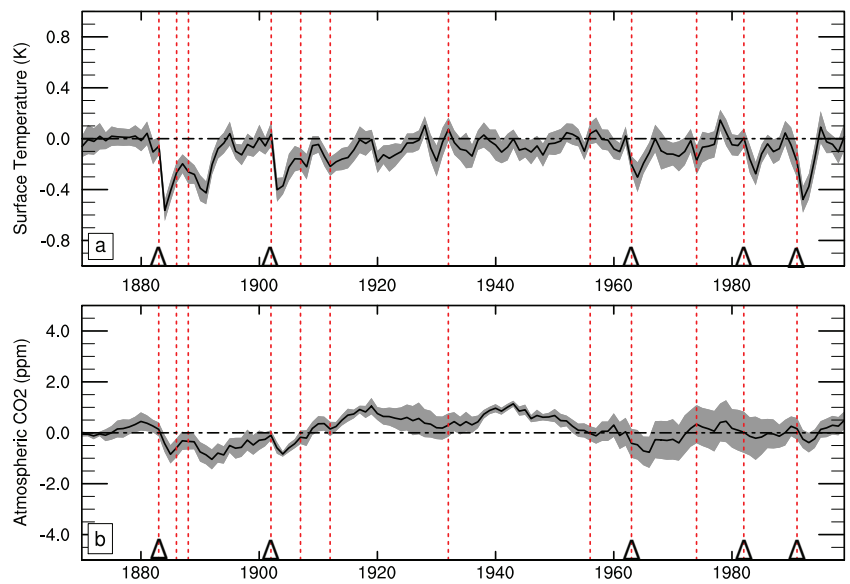

Fig. 1. Globally averaged yearly anomalies for surface temperature (a), $\mathrm{CO}_{2}$ (b), surface flux of carbon to ocean (c) and land (d) from a coupled carbon-climate model, the CCSM3. The model included prescribed volcanic aerosol and prognostic sulfate and carbonaceous aerosol with corresponding emissions and anthropogenic forcings. Shaded area indicates one standard deviation (computed from ensembles of paired runs) above and below anomaly, and dashed vertical red lines indicate years with eruptions from Table 1, with the 5-eruption subset denoted by triangle glyphs. Significant drops in surface temperature and flux of carbon to the land and ocean occur after multiple eruptions (negative flux indicates a flux from the land/ocean to the atmosphere), while there is not as coherent of a signal in the atmospheric $\mathrm{CO}_{2}$ record. The $\mathrm{CO}_{2}$ in the runs plotted here is fully prognostic.

\section{Results}

\subsection{Physical climate response to volcanic forcing}

The CCSM3's dynamical response to volcanic forcing has previously been investigated at higher spatial resolution, but uncoupled to the carbon cycle (Schneider et al., 2009), and there is a great deal of analysis available on the larger eruptions of the past century for other models (Shindell et al., 2004; Robock and Mao, 1995; Stenchikov et al., 2006). In the global average, we expect to see cooling after major eruptions due to the negative radiative forcing of the aerosol particles emitted by the volcano and subsequently dispersed. Here, global surface temperatures drop between 0.4 and 0.8 degrees $\mathrm{C}$ for a short period of time following some eruptions (Fig. 1a); these largest modeled responses occur after three of the four largest eruptions studied here - Krakatau (1883), Santa Maria (1902), and Pinatubo (1991). All of these eruptions had VEIs of 6, and occurred in the tropics.

In response to the Pinatubo eruption in particular, the model here produces transient surface cooling of about $0.5^{\circ} \mathrm{C}$ in the global average, similar to observations (Fig. 2a), regardless of the method chosen to compute the anomalies. The average cold season (October-March) surface temperature response to all 12 eruptions in Table 1 (Fig. 3a) is also
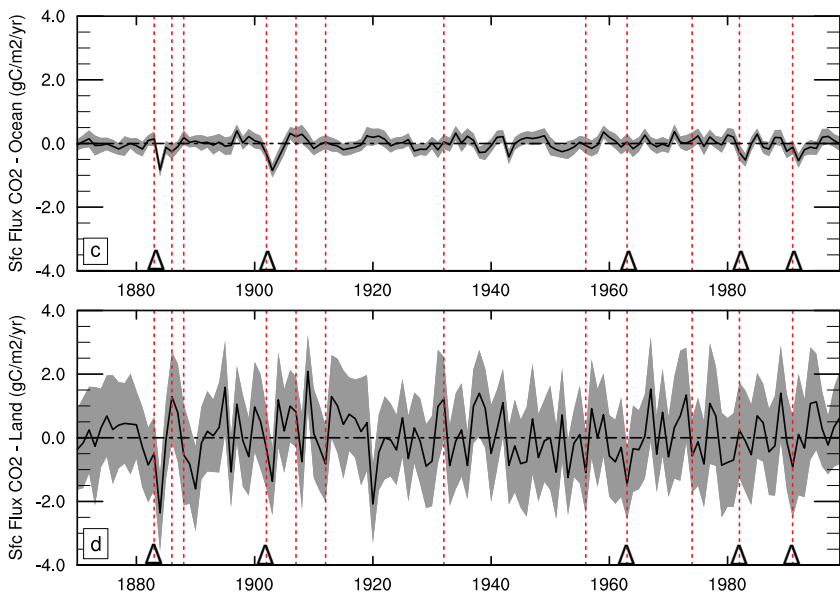

Fig. 1. Continued.
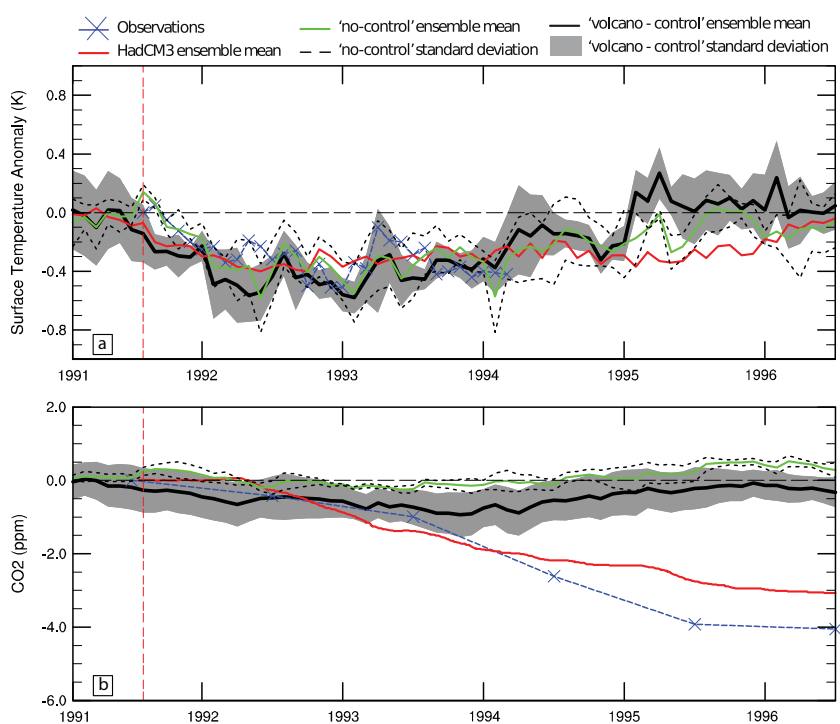

Fig. 2. Globally averaged surface temperature (a) and $\mathrm{CO}_{2}$ (b) anomalies following the eruption of Mt. Pinatubo in 1991 (denoted with a vertical, dashed red line). HadCM3 data (red curve) is from Jones and Cox (2001). Observational data (blue curve with " $x$ " markers) for temperature is from Jones and Kelly (1996); the $\mathrm{CO}_{2}$ observations are the anomalies in atmospheric $\mathrm{CO}_{2}$ at Mauna Loa attributed to volcanic forcing, as estimated in Jones and Cox (2001). Also plotted are anomalies computed using the CCSM3 model with both the "volcano-control" and "no-control" methods.

similar to observations (Shindell et al., 2004) when using the "volcano-control" method to compute the anomalies. However, the "no-control" anomalies fail to capture the spatial patterns in the response seen in observations - weak cooling across much of the globe, with strong cooling in the high latitudes over North America and warming in the high latitudes over Europe and Asia (Shindell et al., 2004). Factors such as the state of ENSO could be a source of variability contributing to differences between the modeled and observed 

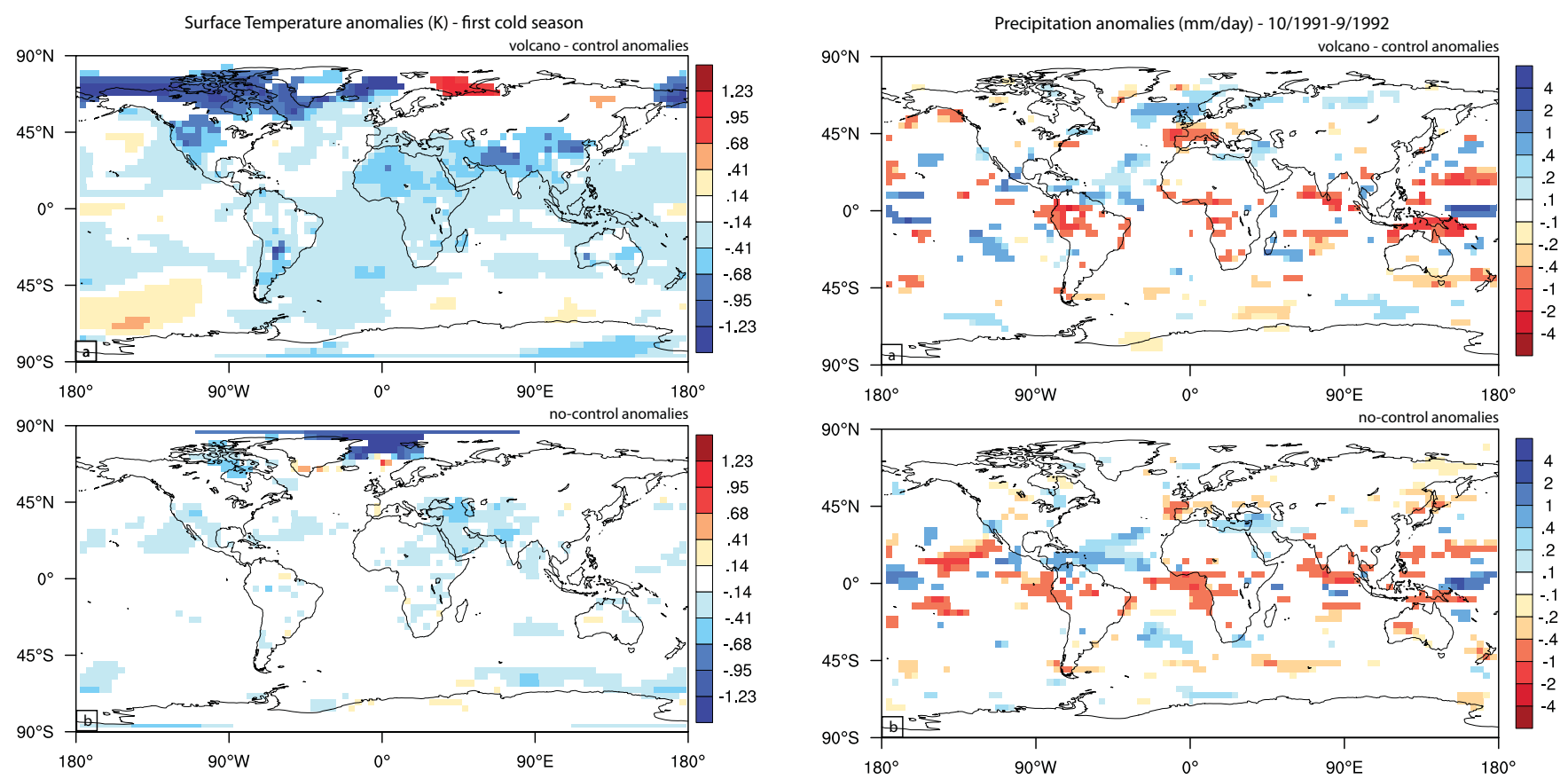

Fig. 3. Modeled surface temperature anomalies during the first Northern Hemisphere cold season following each eruption (October-March), averaged for all twelve eruptions in Table 1. Both anomalies using the volcano-control method (a) and the no-control method (b) are plotted here where significant at the $90 \%$ level.

response here; the model here does not simulate ENSO well (Collins et al., 2006b), and the phase of ENSO in the fully coupled simulations here differs with observations.

The modeled response in precipitation to the Pinatubo eruption (Fig. 4) also bears similarities to the observed response (Trenberth and Dai, 2007). In particular, the model dries in much of the tropics over land. However, the model does not respond as strongly in either wetting or drying as compared to observations (Trenberth and Dai, 2007). The precipitation response over the oceans was not analyzed by Trenberth and Dai (2007), but they are shown here to highlight differences between the two anomaly methods used in this study. The "no-control" anomaly method (Fig. 4b) produces a weaker response over land as opposed to over the ocean, and tends to shift the strong drying responses over South America and sub-Saharan Africa seen in the "volcanocontrol" anomalies (Fig. 4b) towards the oceans bordering these regions to the West.

Averages over the regions of strong surface temperature and precipitation responses (Fig. 5) emphasize the differences between the "volcano-control" and "no-control" anomalies. The surface temperature response (Fig. 5a) differs primarily in Europe and the high latitudes, where the particular spatial pattern juxtaposition of strong cooling and strong warming changes depending on the anomaly method used. The large differences in the precipitation response (Fig. 5b) manifest as greater uncertainty in the regionally-averaged

Fig. 4. Modeled precipitation anomalies during the period October 1991-September 1992. Both anomalies using the volcanocontrol method (a) and the no-control method (b) are plotted here where significant at the $90 \%$ level. Warmer colors indicate dry anomalies.

response for the "no-control" anomalies as compared to the "volcano-control" ones. Furthermore, the regionallyaveraged responses in precipitation to Pinatubo tend to be larger in magnitude than the globally-averaged response, because weak responses outside of these regions tend to diminish the magnitude of the globally-averaged response. These regional differences, though, might also be influenced by the phase of ENSO and other variability between ensemble members, and the responses might not be robust due to the small number of ensemble members used to compute them.

\subsection{Biogeochemical responses to the Pinatubo eruption}

The response in surface mean atmospheric $\mathrm{CO}_{2}$ concentrations (Fig. 1b) following the eruptions is not as coherent as the response in surface temperature, but the three large eruptions with the greatest surface temperature anomalies are followed by decreases in atmospheric $\mathrm{CO}_{2}$. Sarmiento (1993) noted that the growth rate of atmospheric $\mathrm{CO}_{2}$ decreased for a short period following Pinatubo - a feature reproduced here in these model runs. Interestingly, in periods without volcanoes (around 1920 and 1940, for example), the $\mathrm{CO}_{2}$ in the volcano runs exhibits a statistically significant positive anomaly of about $1 \mathrm{ppm}$ above the control runs. This suggests that the carbon dioxide reduction is temporary and in some way is compensated for during volcanically quiet periods. Statistically significant responses in both land and ocean 


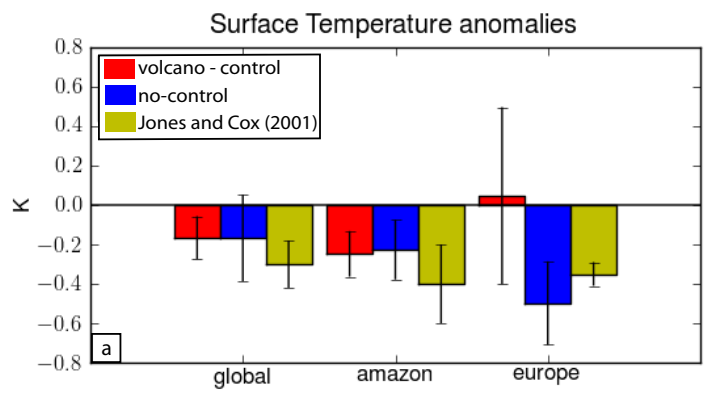

Precipitation anomalies

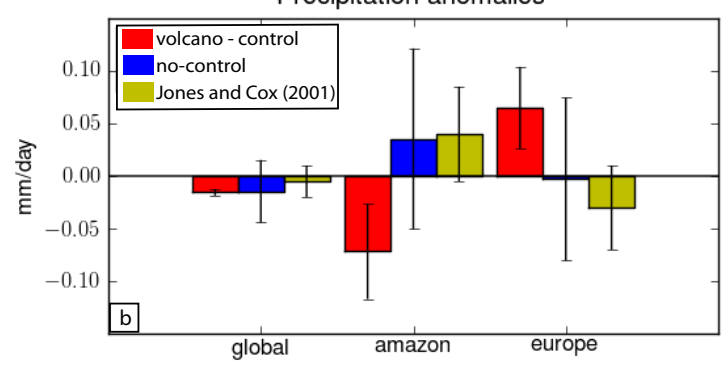

Fig. 5. Global and regional (Amazon: $90^{\circ} \mathrm{W}-60^{\circ} \mathrm{W}, 30^{\circ} \mathrm{S}-$ $15^{\circ} \mathrm{N}$; Europe: $15^{\circ} \mathrm{W}-35^{\circ} \mathrm{E}, 50^{\circ} \mathrm{N}-70^{\circ} \mathrm{N}$ ) surface temperature (a) and precipitation (b) responses to the Pinatubo eruption for the model here (red and blue) and for the model used by Jones et al. (2001) (yellow), averaged over December 1990-December 1996. The mean response averaged over land gridpoints in these regions over the months following the eruption is indicated by the colored bars, and the standard deviation of the spatially-averaged responses is given by the corresponding error bars.

fluxes of $\mathrm{CO}_{2}$ are seen for many, but not all, volcanic eruptions (Fig. 1c-d) - most noticeably for the larger eruptions of Krakatau, Santa Maria, and El Chichón, but not for Pinatubo.

While the physical response to volcanoes in the model is similar to observations - especially for temperature - it is slightly weaker in precipitation (Sect. 3.1). There was not a significant response in atmospheric $\mathrm{CO}_{2}$ in the model (Fig. 2b). This could be due to the weak precipitation response, or due to the low climate feedback of carbon in this model (Thornton et al., 2009), and an insensitivity of the modeled carbon cycle to changes in the physical climate over short periods of time. This potentially represents a serious error in the model. Similar models with a relatively small carbon feedback have shown a larger atmospheric $\mathrm{CO}_{2}$ response, even where the precipitation response was weak (Frölicher et al., 2011).

Jones and Cox (2001) used the Pinatubo eruption to analyze the sensitivity of the carbon cycle in a coupled carbonclimate model, the HadCM3. Their model (Fig. 5, blue bars) behaves differently in its climate, carbon cycle, and aerosol response than the model used in this study (Thornton et al., 2009; Mahowald et al., 2011). While both models produce strong surface cooling in response to Pinatubo, the model here responds more strongly with respect to reduced precipitation across much of the globe. This difference is most
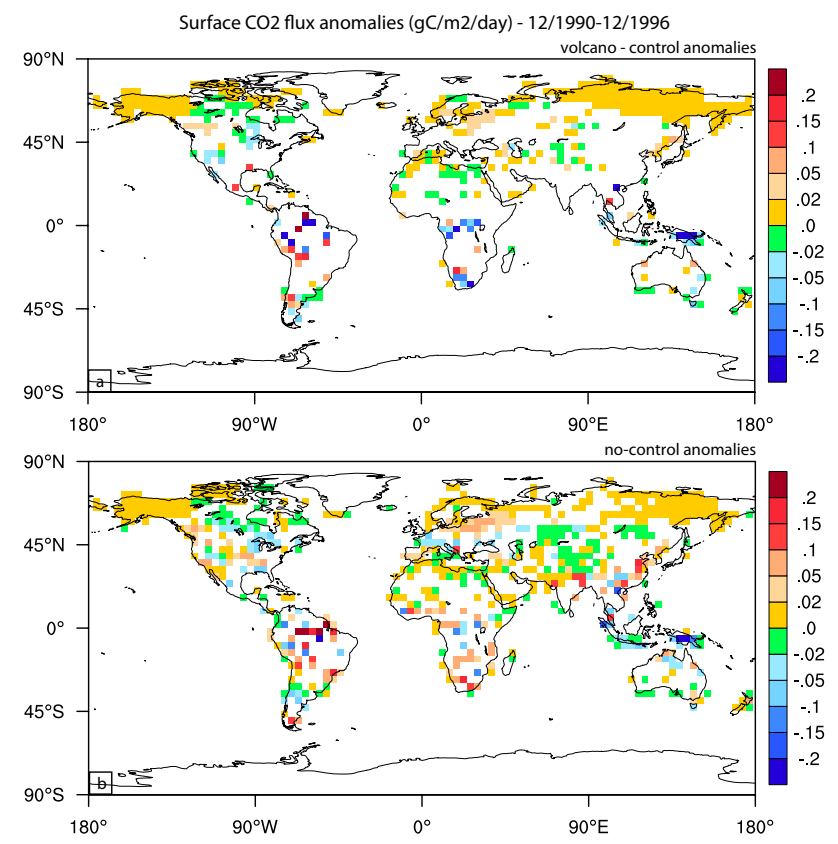

Fig. 6. Surface flux of $\mathrm{CO}_{2}$ anomalies over land, averaged over the period December 1990-December 1996. Both anomalies using the volcano-control method (a) and the no-control method (b) are plotted here where significant at the $90 \%$ level. Positive here (warm colors) denotes uptake of carbon by the land.

prominent in the Amazon, where the model used by Jones and Cox (2001) produces large increases in precipitation while our model sees a large decrease (Fig. 5b). Observations suggest precipitation decreased in this region following Pinatubo (Trenberth and Dai, 2007), indicating that the model simulations presented here have a more accurate precipitation response than Jones and Cox (2001).

The model used by Jones and Cox (2001) also responds differently in terms of the surface flux of $\mathrm{CO}_{2}$ to the atmosphere; their model increases land uptake of $\mathrm{CO}_{2}$ over much of the tropics in Africa and South America in response to the eruption of Pinatubo. The model here has a less coherent response (Fig. 6), with a great deal of spatial variability. The largest response in both models occurs in the tropics with only a small signal in the mid and high latitudes of either hemisphere (Jones and Cox, 2001). This analysis was repeated for shorter 1-yr and 2-yr time periods following the Pinatubo eruption, and while these shorter time periods had more significant and larger anomalies (greater than $\pm 0.02 \mathrm{gC} \mathrm{m}^{-2} \mathrm{day}^{-1}$ ), the spatial variability did not change. The "no-control" anomalies (Fig. 6b) tend to produce weaker uptake of $\mathrm{CO}_{2}$ throughout a larger part of the globe.

These changes in uptake of atmospheric $\mathrm{CO}_{2}$ motivate an analysis of the modeled carbon cycle and oceanic/terrestrial biosphere. In the global average, there was a net global reduction in gross and net primary production and heterotrophic respiration in the model following Pinatubo, but 

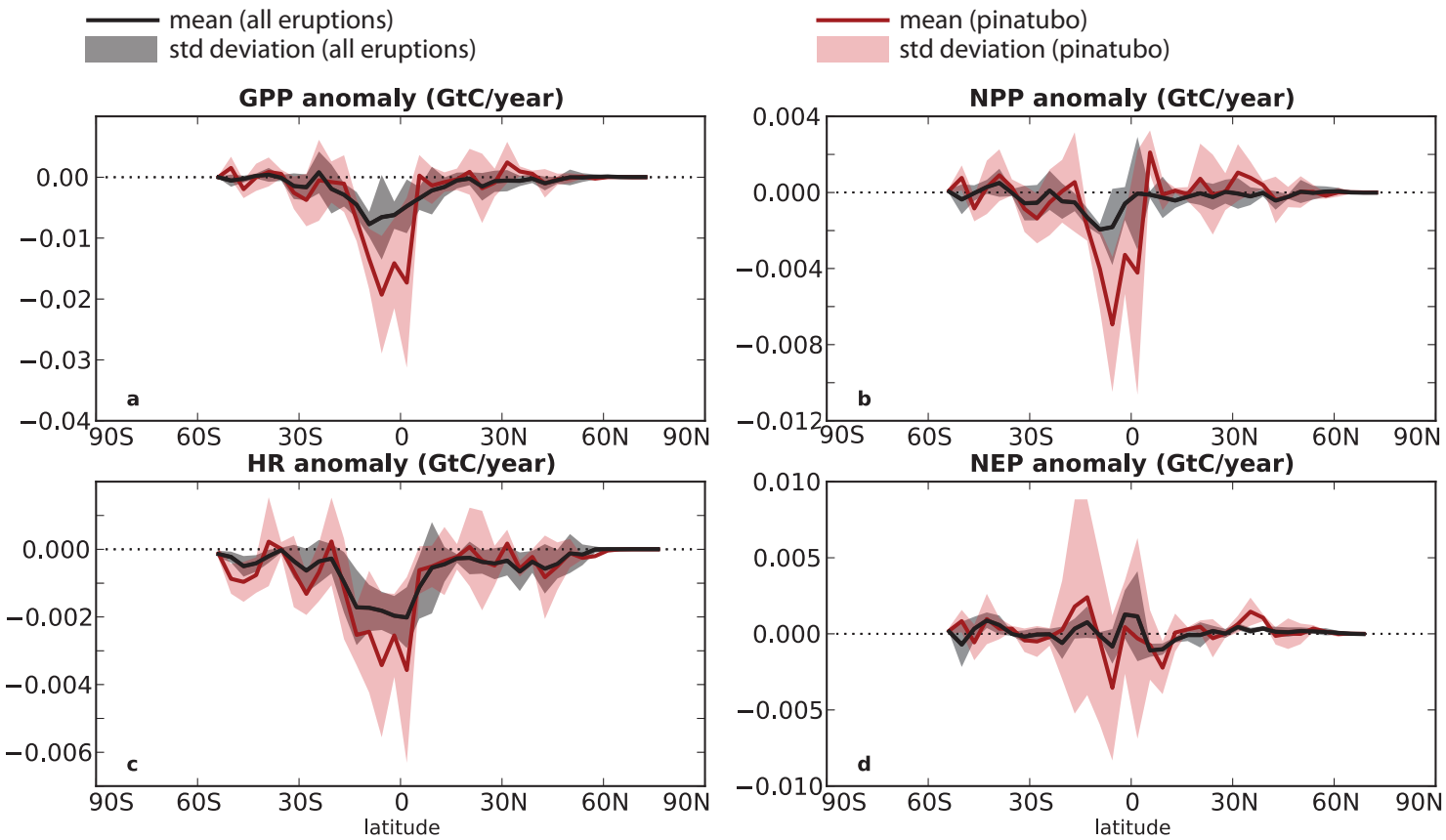

Fig. 7. Zonal mean anomalies in factors contributing the uptake of $\mathrm{CO}_{2}$ from the atmosphere, computed by using the volcano anomaly method for Pinatubo (red) and the mean of several eruptions (black), averaged over the two years following the eruption(s). The shaded area represents one standard deviation above and below the means.

no significant response in net ecosystem production. The response in the low latitudes - particularly in the Amazon - (Fig. 7) dominates the global response. In contrast, the Jones and Cox (2001) simulations show significant terrestrial uptake of $\mathrm{CO}_{2}$ associated with increased net primary production and net ecosystem productivity, especially in the Amazon. In the global average, though, a decrease in heterotrophic respiration in their model contributes significantly to increases net ecosystem productivity.

The decreases in the modeled gross primary production are associated with anomalous decreases in both surface temperature and precipitation, and potentially increases in diffuse radiation (Fig. 5b) in both the global average and in the Amazon, although this response to changing diffuse radiation is opposite what should be expected (Thornton and Zimmermann, 2007). Decreases in precipitation and surface temperature appear in the the observational record following Pinatubo (Hansen et al., 1996; Trenberth and Dai, 2007). A different response occurs in the model used by Jones and Cox (2001); their model produces realistic surface cooling, but no significant response in precipitation. In particular, in the Amazon their model's response to Pinatubo features possibly enhanced precipitation (Jones and Cox, 2001), which is not consistent with the data (Trenberth and Dai, 2007). However, Pintatubo coincided with an El Niño event which would have reduced precipitation over the Amazon; taking this into account, it is difficult to attribute our model's response directly to the Pinatubo eruption, since we can not force the exact same phase of El Niño in each ensemble member. A detailed analysis of the mechanisms for the response of land carbon to aerosols, and specifically volcanic aerosols, is important for understanding the carbon cycle and aerosol interactions, but this topic is beyond the scope of this study. However, it is interesting that the dominant response in Jones and Cox (2001) is in the Amazon, where the precipitation response is opposite that of the observations: this raises the possibility that their model results obtain the right result, but potentially for the wrong reasons.

Unfortunately, there are limited observations available to compare these modeled responses against. Grace et al. (1995) documented local and significant uptake of carbon in the Amazon rainforest between 1992 and 1993, which is seen in the modeled regional Amazon mean but not at a significant level, and in some limited regions of the Amazon where there is a modeled uptake of carbon. These responses in the Amazon again tend to dominate the zonal response in the low latitudes, with contributions from Oceania and sub-Saharan Africa (Fig. 7). In addition to the zonal response, net primary production decreased in sub-Saharan Africa in the model following Pinatubo by $-0.1 \pm 0.07 \mathrm{GtC} \mathrm{yr}^{-1}$ when integrated solely over that region. By contrast, the signal over all the land in the tropics $\left(30^{\circ} \mathrm{N}-30^{\circ} \mathrm{S}\right)$ was slightly stronger and opposite in sign, $0.46 \pm 0.1 \mathrm{GtC} \mathrm{yr}^{-1}$. Tree ring records indicate a decline in growth in Northern Hemisphere forests following Pinatubo (Krakauer and Randerson, 2003) and in temperate North America, while in the model simulations of 


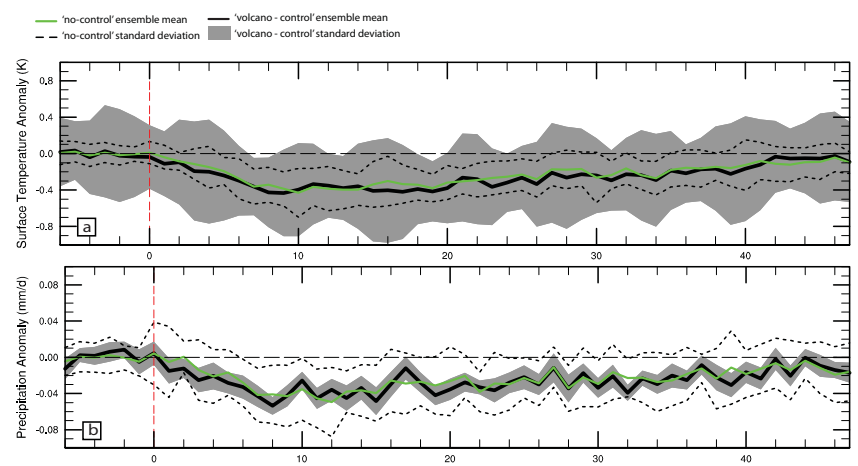

Fig. 8. Globally averaged (a-b) and integrated (c-g) monthly anomalies for the indicated variables, computed using both the "volcano-control" and "no-control" methods, averaged and composited for the 5 denoted eruptions in Table 1. Mean anomalies for each method are depicted with black and green lines, respectively, and the corresponding standard deviation is shown as a shaded area ("volcano-control") and dotted lines ("no-control"). X-axis is months after eruption (dashed red line). Positive surface flux indicates uptake by land/ocean.

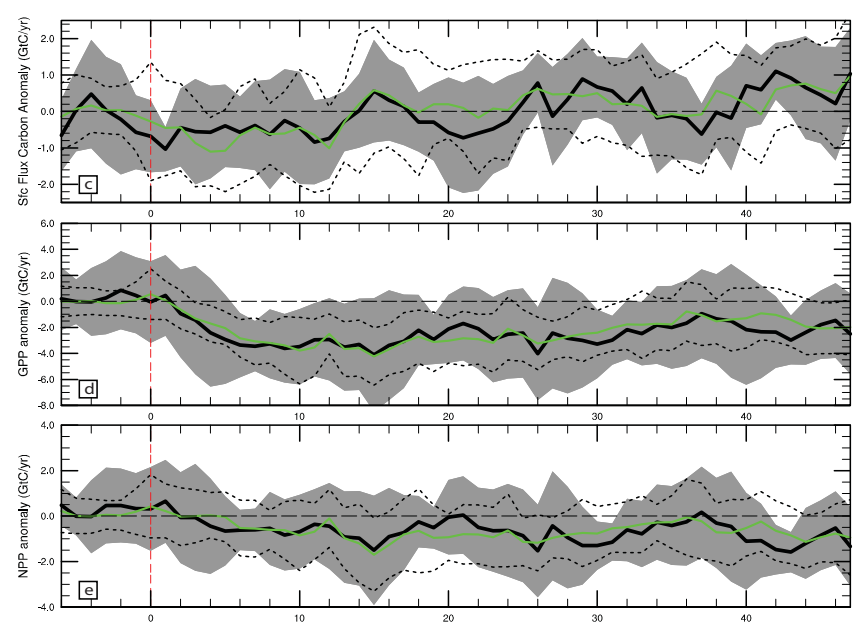

Fig. 8. Continued.

North America there are some regions with an increase in uptake as well as some with a decrease. The growth rate of atmospheric $\mathrm{CO}_{2}$ slowed after the Pinatubo eruption, which is consistent with a net uptake of $\mathrm{CO}_{2}$ by the land and oceans in the years after the eruption (Sarmiento et al., 2010), as seen in these simulations, although the signal was not statistically significant (Fig. 2b). In the model runs here, the terrestrial biosphere does not become a source of carbon to the atmosphere following Pinatubo, but we generally see an insignificant decrease in the land's uptake of carbon after the eruption - a result consistent with albeit smaller than previous studies (Jones and Cox, 2001; Frölicher et al., 2011).

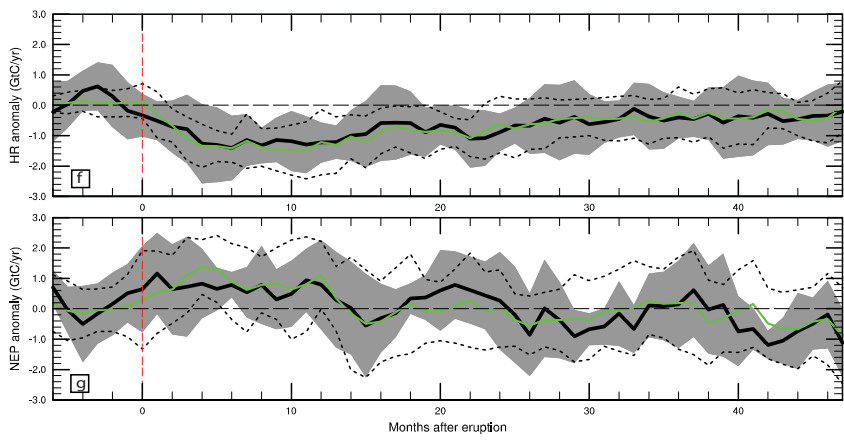

Fig. 8. Continued.

\subsection{Average responses to volcanic eruptions}

\subsubsection{Globally averaged response}

Similar to the modeled response to Pinatubo, in the average of the subset of 5 eruptions from Table 1, surface temperatures and precipitation decrease following volcanic events (Fig. 8a-b). The same response is seen in the average of all the eruptions in Table 1, but it is smaller in magnitude and more variable between eruptions. This is partly because the selection of events spans eruptions which happened at different latitudes and different times in the year.

Although there is a slight decrease in the flux of carbon into the land, there is not a statistically significant change in the modeled terrestrial or oceanic uptake of carbon following these eruptions (Fig. 8c and d). However, the terrestrial biosphere does respond in some ways. Gross primary production decreased after the eruptions, particularly in the anomalies computed using the "no-control" method (Fig. 8e). This did not translate to significant signals in net primary production (Fig. 8f), although heterotrophic respiration decreased (Fig. 8g). A small increase in net ecosystem productivity (Fig. 8h) was seen in response to the eruptions, as was a small, but not statistically significant, increase in the flux of carbon to the atmosphere due to fires (Fig. 8i).

These averaged responses are somewhat damped compared to some of the individual eruptions' responses (not shown). This is partly due to the eruptions occurring at different times of the year; cooling or precipitation in different parts of the growing season impact vegetation differently (Fig. 8c-h). Overall, a composite of the model's response to volcanoes suggests that gross primary production is reduced as is plant respiration, which leaves net primary production slightly reduced but not statistically significant. Because of the reduction in heterotrophic respiration, net ecosystem productivity is actually enhanced slightly, although much of the time this increase is not statistically significant. Note that most of these signals can be seen in both the "volcanocontrol" as well as the "no-control" anomalies. 

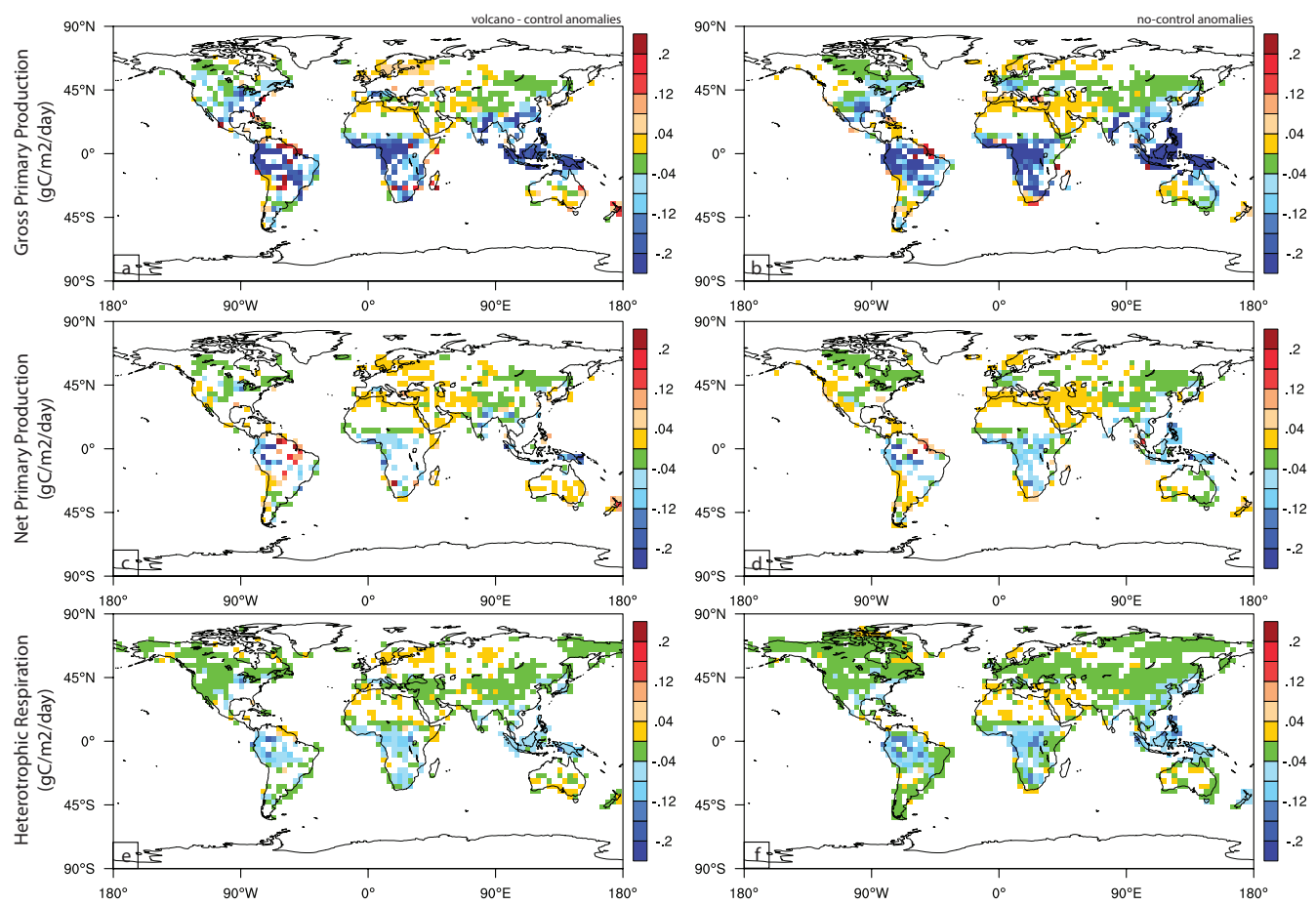

Fig. 9. Gridded average anomalies for the indicated modeled variables, averaged over the subset of 5 eruptions in Table 1 for the two-year period following each eruption. Only anomalies at the $90 \%$ significance level are shown here. All the anomalies in the left-column are computed with respect to the control run; all the anomalies in the right-column use the "no-control" method. The variable plotted in each row is on the far left - gross primary production $(\mathbf{a}-\mathbf{b})$, net primary production $(\mathbf{c}-\mathbf{d})$, heterotrophic respiration $(\mathbf{e}-\mathbf{f})$, moisture stress $(\mathbf{g}-\mathbf{h})$, net ecosystem productivity (i-j), and surface flux of carbon (k-l). Positive flux in (k-l) indicates uptake of carbon by land.

\subsubsection{Regional responses}

Since the responses seen in Fig. 8 tended to be transient and last no more than two years, gridded average anomalies were computed for the first two-year period following each eruption and averaged over the subset of 5 eruptions in Table 1 (Fig. 9).

The global signal in the carbon cycle's response to volcanic eruptions is dominated by responses in the tropics. Gross primary production is significantly reduced in the tropics regardless of the anomaly method chosen (Fig. 9a-b). Since gross primary production is a measure of photosynthesis at the ecosystem level, total growth and autotrophic respiration in tropical ecosystems in the model is reduced following volcanic eruptions. Generally, the modeled net primary production is also decreased in these regions (Fig. 9c-d), but not as much as gross primary production. The rate at which plants return carbon during metabolism to the atmosphere as $\mathrm{CO}_{2}$, autotrophic respiration (AR), is equal to gross primary production (GPP) minus net primary production (NPP) $(A R=G P P-N P P)$. Since the modeled reductions in net primary production are less than those in gross primary production, this implies from the modeled response to the eruptions that there is a net increase in the amount of carbon returned to the atmosphere via plant metabolism.
However, a reduction in heterotrophic respiration (HR) (Fig. 9e-f) is also seen in the modeled response to the eruptions; heterotrophic respiration measures the rate at which carbon is released to the atmosphere by the decomposition of organic matter in the soil, so a reduction in this component would reduce the amount of carbon being released to the atmosphere. Ultimately, the net ecosystem productivity (NEP) throughout much of the world increases in response to the eruptions $(\mathrm{NEP}=\mathrm{NPP}-\mathrm{HR})($ Fig. $9 \mathrm{i}-\mathrm{j})$, albeit weakly outside of isolated regions in the Amazon and sub-Saharan Africa. Thus, in the modeled response to the eruptions, the terrestrial ecosystem becomes a net sink of atmospheric $\mathrm{CO}_{2}$, which leads to a weak but significant uptake of carbon dioxide by the terrestrial biosphere from the atmosphere (Fig. 9k1). NPP went down, but HR went down more, leaving more carbon on land.

There are not large discrepancies between the anomalies computed with the "volcano-control" method versus those computed with the "no-control" method in these results. In general, the "no-control" method yields more grid boxes with statistically significant anomalies, which tend to show up in the globally-averaged results as an increase in the variance around the ensemble mean modeled response for a given variable. 

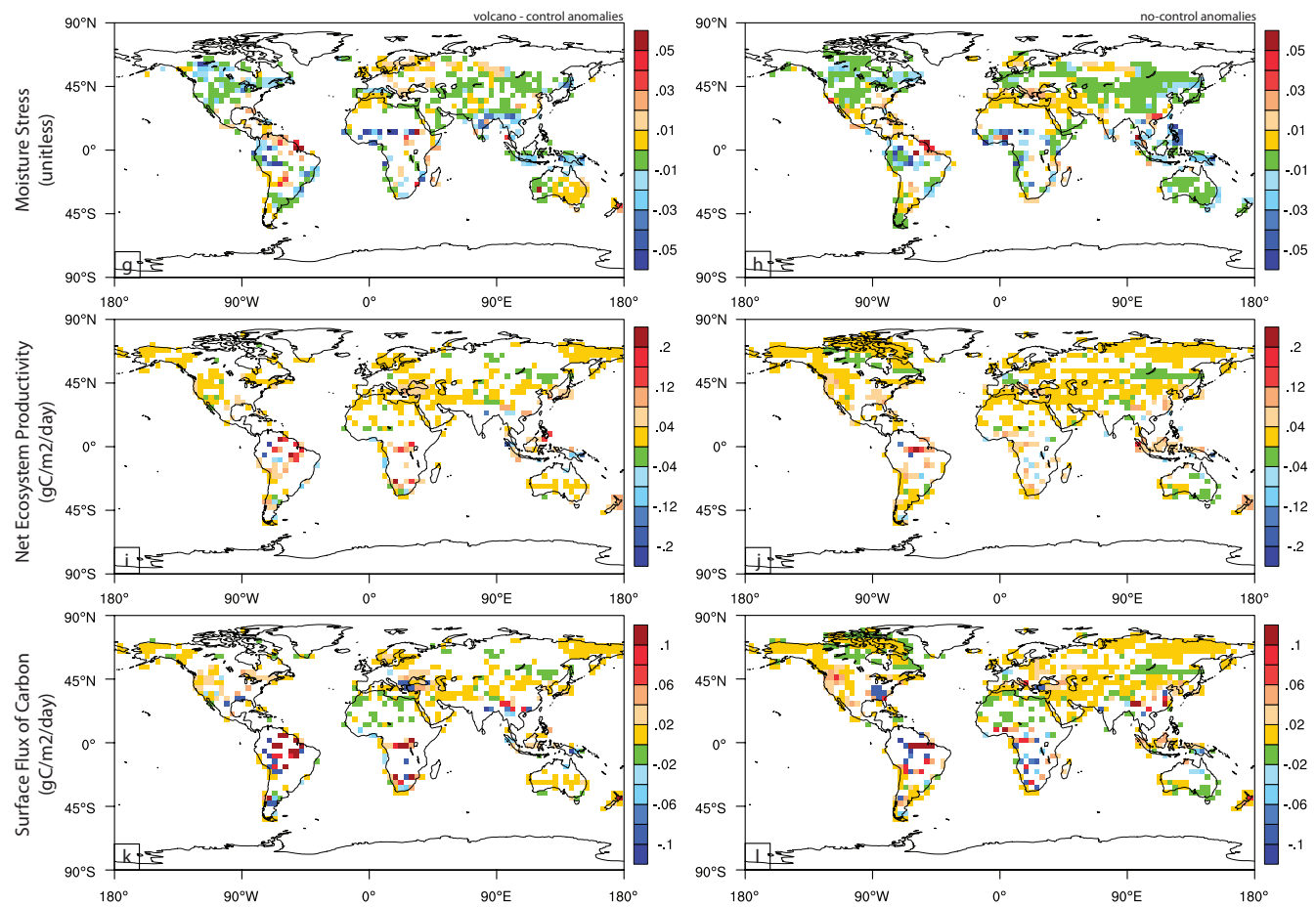

Fig. 9. Continued.

To illustrate how the modeled response varies with latitude, zonal means were computed over the two-year period following the eruption for several factors contributing to the uptake of $\mathrm{CO}_{2}$ (Fig. 7). The response is strongest in the tropics and low latitudes, dominated by signal in the Amazon, oceanic continent, and sub-Saharan Africa, with significant decreases in gross primary, heterotrophic respiration, and net primary production. The response for Pinatubo alone is stronger than the multi-eruption mean (subset in Table 1). In the zonal average, there is no longer a significant response in net ecosystem productivity, although spatial heterogeneity in the response to the eruptions could be masking some signal here.

\subsection{Ocean responses}

The ocean biogeochemical response to volcanoes could be due to changes in temperature, winds, mixed layer depth, cloudiness and subsurface nutrient supply (Fig. 10), and here we neglect atmospheric deposition of nutrients. For nitrogen fixation, the Pacific tends to be iron limited, while the Atlantic tends to be phosphorous limited; thus, changes in nitrogen fixation, denitrification and net primary productivity (NPP) can have multiple factors (Fig. 10b-c). Off the west coast of North America, both net primary production (Fig. 10a-b) and nitrogen fixation (Fig. 10c-d) show a shift, with increases in both off the coast and decreases surrounding, although the nitrogen fixation pattern is slightly offset from the NPP change. The increase in nitrogen fixation is associated with a decrease in iron limitation due to an increase in dust deposition (Fig. $10 \mathrm{~g}-\mathrm{h}$ ). In the region where production increased, a decrease in outgassing of $\mathrm{CO}_{2}$ also occurred (Fig. 10k-1). In the North Atlantic, there is also an increase associated with a shift in nitrogen fixation. A time series analysis of the difference in productivity in the volcano and control runs suggest that averaged over regions, volcanoes are not significant drivers of changes in productivity (Fig. 11); the response to different volcanoes can be an increase or a decrease in productivity. A similar result is seen in the response of denitrification and nitrogen fixation of the ocean model to volcanoes (not shown). Overall, the oceanic biogeochemistry response to the eruptions is weaker than that on the land, although we ignore in these simulations the potentially important impact of direct deposition of nutrients in ash and lava into the ocean from the volcanoes.

For many of the most important signals, there is good agreement between the "volcano-control" and "no-volcano" anomalies. In the future, a more detailed study focused on the ocean - including the effects of volcanic inputs on biogeochemical species - will be completed.

\section{Summary and discussion}

An ensemble of model runs using the coupled climatecarbon NCAR Community Climate System Model Version 3 were integrated over the time period 1870-2000 to investigate the response to volcanic eruptions. This study compares 

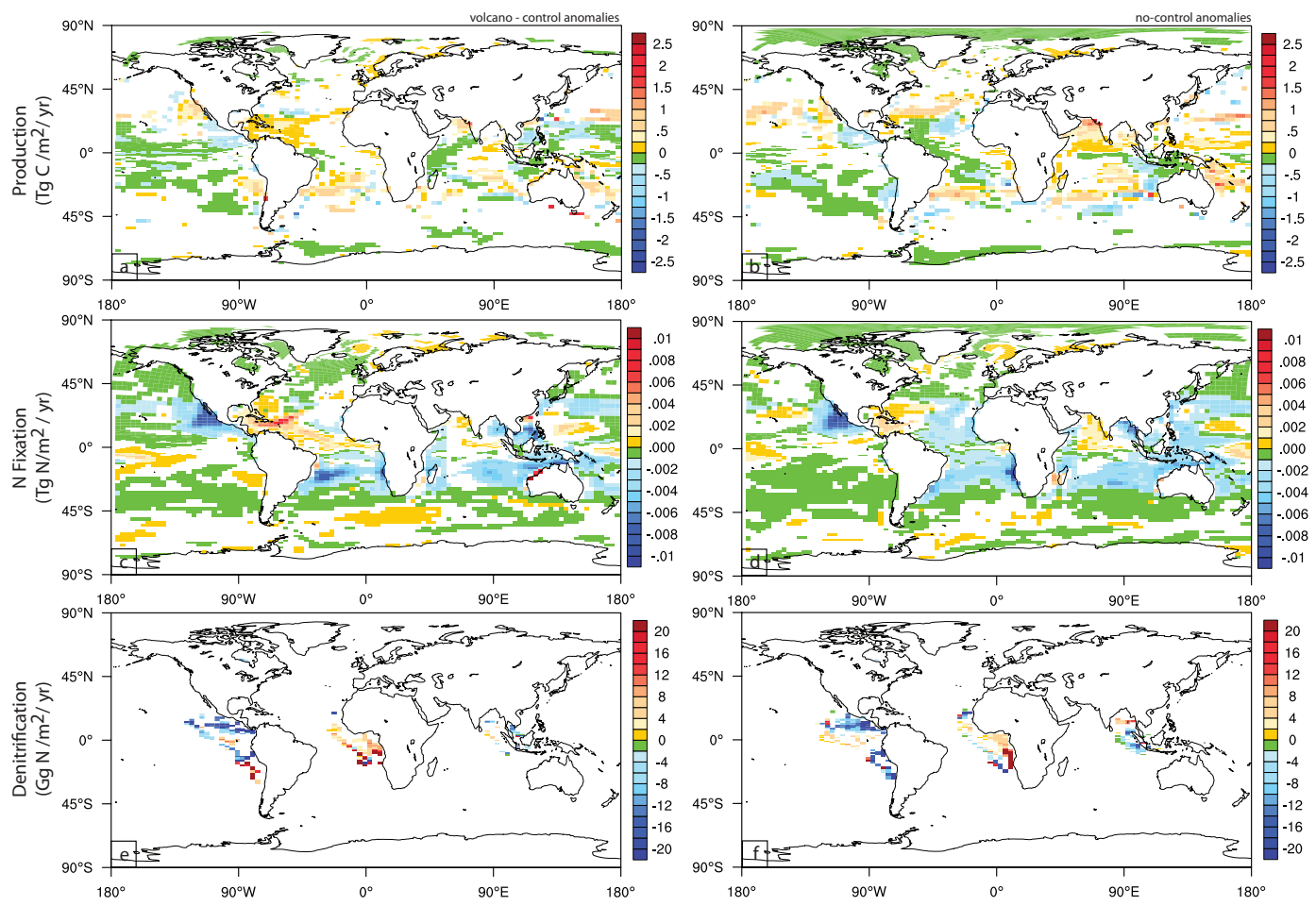

Fig. 10. Gridded ocean anomalies, averaged over the subset of 5 eruptions in Table 1 for the two-year period immediately following the eruptions. Only anomalies significant at the $90 \%$ level are drawn. Globally, the modeled ocean response is weak, but there are small regions of substantially stronger responses, such as the large zones of decreased or increased nitrogen fixation on either side of Central America.
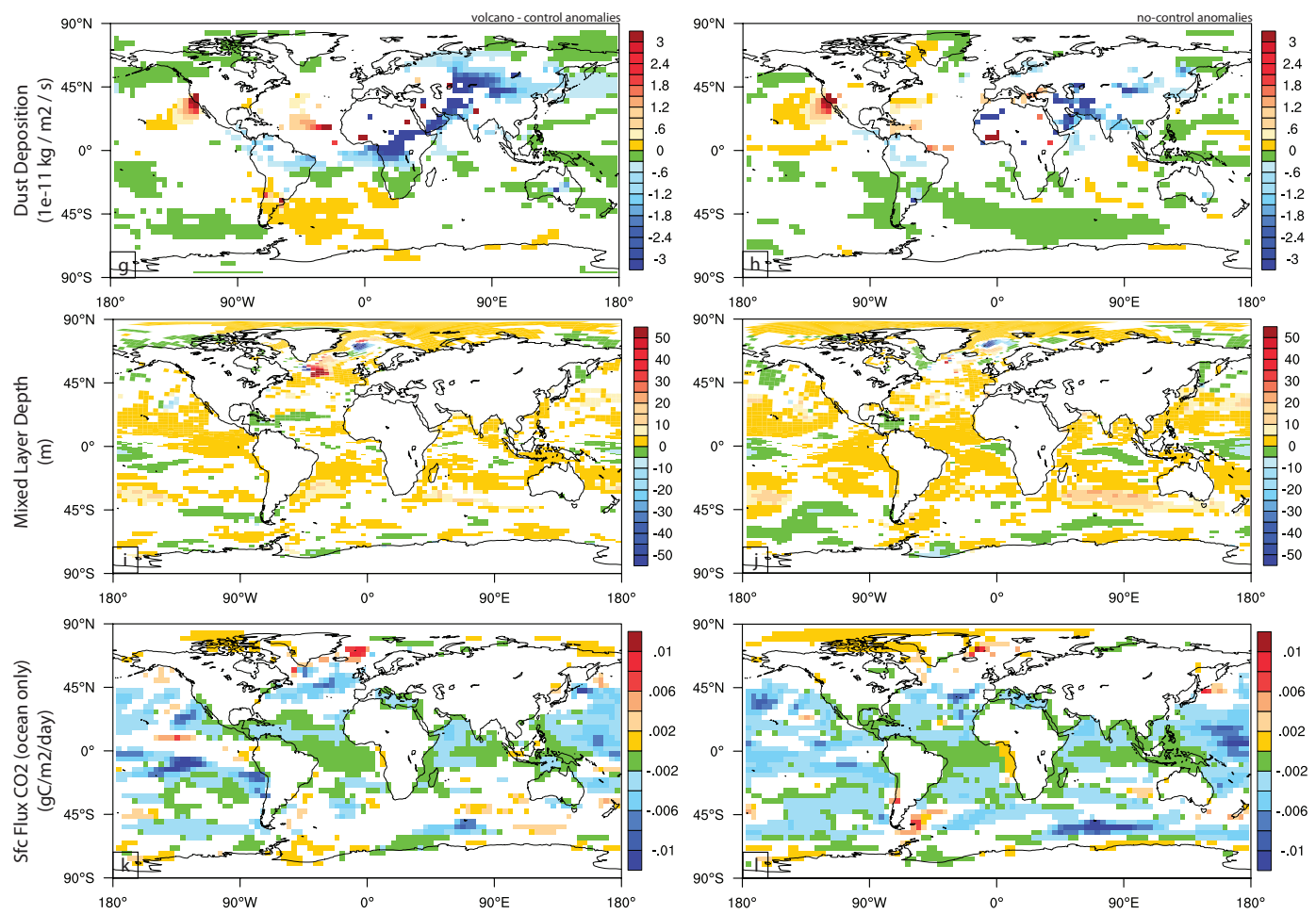

Fig. 10. Continued. 

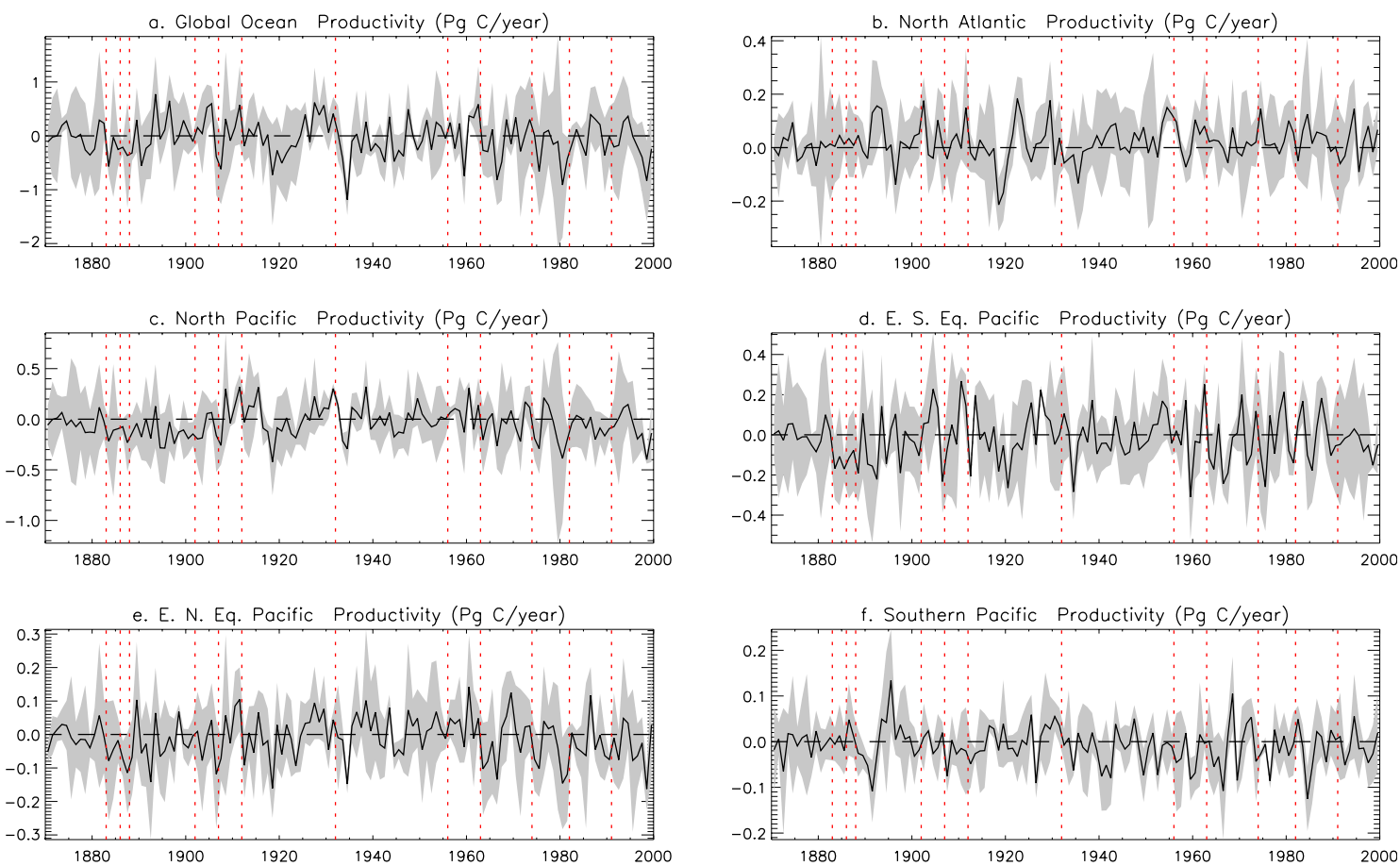

Fig. 11. Changes in ocean productivity $\left(\mathrm{Pg} \mathrm{yr}^{-1}\right)$ for $1870-2000$ in the volcano minus control cases. Eastern South equatorial Pacific is defined as $220^{\circ} \mathrm{E}-280^{\circ} \mathrm{E}, 20^{\circ} \mathrm{S}-0^{\circ} \mathrm{N}$; eastern North equatorial Pacific is defined as $220^{\circ} \mathrm{E}-280^{\circ} \mathrm{E}, 0-20^{\circ} \mathrm{N}$.
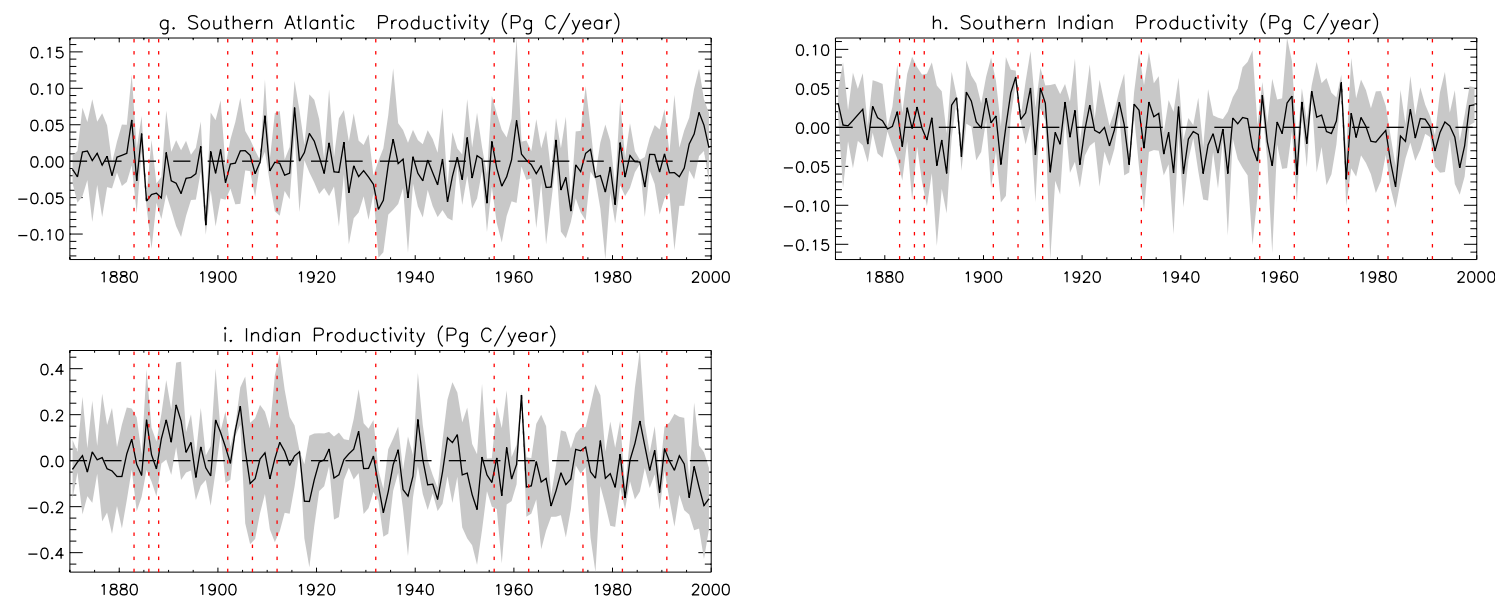

Fig. 11. Continued.

the CCSM3 response to volcanoes in the coupled carbon cycle framework to observations following Pinatubo, as well as extends previous studies (Jones and Cox, 2001) by looking at more eruptions.

In addition, we examine the ability to detect volcanic signals in cases without a control simulation. In the real world, there is no control case. Control cases represent expensive computation runs; thus, deducing what part of the full response to volcanoes is possible to estimate from one simulation provides insight into model evaluation using volcanoes. The analysis here suggests that the globally averaged temperature and carbon dioxide response, as well as the regional scale response in temperature and carbon dioxide fluxes, are seen in the "no control" cases, even in the case shown here with a very weak response to the carbon cycle.

The model reproduces the expected reduction in globally averaged temperatures and globally averaged precipitation in a statistically significant manner for a short duration following the eruptions (Shindell et al., 2004; Trenberth and Dai, 2007). These dynamical responses are consistent with previous studies using this model (Schneider et al., 2009). 
The model here produces surface cooling in response to the Pinatubo eruption similar in magnitude to the observed response. It also produces a statistically significant decrease in precipitation across the globe following the eruption as in the observational record, although precipitations responses are weaker than deduced from observations (Trenberth and Dai, 2007).

The physical climate response affects the response in the terrestrial biosphere. The growth rate of atmospheric $\mathrm{CO}_{2}$ slowed after the Pinatubo eruption, which is consistent with a net uptake of $\mathrm{CO}_{2}$ by the land and oceans in the years after the eruption (Sarmiento, 1993). These responses are broadly consistent with the model result. The carbon response in this model is weaker than seen in the observations or other model simulations (e.g. Jones et al., 2001). In another model, the HadCM3, there is a stronger net terrestrial uptake of carbon following the Pinatubo eruption, primarily associated with increases in gross primary production and net ecosystem productivity especially in the Amazon (Jones et al., 2001). However, the HadCM3 model simulates an increase in precipitation, while observations and the model presented here show a decrease in precipitation in the Amazon, calling into question the robustness of their result, although removing the effects of El Niño is difficult and may be the cause of the differences. The model here responds differently, with significant decreases in gross primary production and respiration, resulting in a weak response in net ecosystem productivity. Furthermore, the model used by Jones et al. (2001) has strong coherence in its response, especially in South America and sub-Saharan Africa. The model here has far more spatial variability in its response than the Jones and Cox (2001) or Brovkin et al. (2010) studies in those same regions - particularly in South America.

It is not clear exactly why or where the model presented here is getting the $\mathrm{CO}_{2}$ response wrong. There are not a large number of observations against which to compare the modeled volcanic response in the carbon cycle, but the model responds by weakly increasing the uptake of $\mathrm{CO}_{2}$ from the atmosphere, particularly in South America. Grace et al. (1995) documented local, significant uptake of carbon in the Amazon rainforest between 1992 and 1993, while Krakauer and Randerson (2003) noted that tree ring records indicate that there was a decline in growth in Northern Hemisphere forests following Pinatubo. Other models (Jones et al., 2001; Brovkin et al., 2010) obtain a stronger response in the tropics, suggesting that is the main region of discrepancy in the model. However, the modeled weak response to a climate perturbation is consistent with the low climate impact on the carbon cycle seen previously (Thornton et al., 2009), and suggests that volcanoes do provide insight into the climatecarbon feedback, as previously argued (Jones et al., 2001; Friedlingstein and Prentice, 2010). The weak carbon-climate feedback in this model has been linked to strong nitrogen co-limitation (Thornton et al., 2009), but in this paper is shown to be relatively insensitive to timescale: it is similar in response to volcanoes or long-term climate change. More data and approaches are needed in order to constrain the volcanic response; for example, the use of carbon isotopes (Welp et al., 2011) to better estimate biosphere-atmosphere exchanges.

In the composite of the set of eruptions analyzed in this study, a similar story emerges to that seen when just analyzing Pinatubo. Again, in the global average, there is a significant reduction in both respiration and gross primary production in the mean response to volcanic eruptions, as well as a small but non-significant increase in net ecosystem productivity, indicating a small uptake of carbon by the terrestrial biosphere from the atmosphere after the eruptions. This response is most prominent when averaged over the first two years following the eruptions, and is consistent throughout the tropics. This average response is also consistent with the modeled response to Pinatubo but slightly larger when averaged over many eruptions. The carbon response of the ocean is smaller than that of the land in these simulations, similar to previous studies (Jones and Cox, 2001; Brovkin et al., 2010); however, these studies ignore the potentially important effects of the addition of biogeochemically relevant species in the volcanic ash (e.g., Watson, 1997) in terms of the nutrients they add to the ocean. This will be the focus of future work.

Acknowledgements. This work was done under the auspices of NASA NNGO6G127G and NSF grants (1049033, 1021614). S.C.D. acknowledges support from NASA NNX07AL80G. Computer time was obtained from the National Center for Atmospheric Research, a National Science Foundation facility.

Edited by: G. Bala

\section{References}

Adams, J. B., Mann, M. E., and Ammann, C. M.: Proxy evidence for an El Nino-like response to volcanic forcing, Nature, 426, 274-278, doi:10.1038/nature02101, 2003.

Ammann, C. M., Meehl, G. A., Washington, W. M., and Zender, C. S.: A monthly and latitudinally varying volcanic forcing dataset in simulations of 20th century climate, Geophys. Res. Lett., 30, 1657-1671, doi:10.1029/2003GL016875, 2003.

Bousquet, P., Peylin, P., Ciais, P., Le Quéré, C., Friedlingstein, P., and Tans, P. P.: Regional Changes in Carbon Dioxide Fluxes of Land and Oceans Since 1980, Science, 290, 1342-1346, doi:10.1126/science.290.5495.1342, 2000.

Brovkin, V., Lorenz, S. J., Jungclaus, J., Raddatz, T., Timmreck, C., Reick, C. H., Segschneider, J., and Six, K.: Sensitivity of a coupled climate-carbon cycle model to large volcanic eruptions during the last millennium, Tellus B, 62, 674-681, doi:10.1111/j.1600-0889.2010.00471.x, 2010.

Collins, W. D., Bitz, C. M., Blackmon, M. L., Bonan, G. B., Bretherton, C. S., Carton, J. A., Chang, P., Doney, S. C., Hack, J. J., Henderson, T. B., Kiehl, J. T., Large, W. G., McKenna, D. S., Santer, B. D., and Smith, R. D.: The Community Climate 
System Model Version 3 (CCSM3), J. Climate, 19, 2122-2143, doi:10.1175/JCLI3761.1, 2006a.

Collins, W. D., Rasch, P. J., Boville, B. A., Hack, J. J., McCaa, J. R., Williamson, D. L., Briegleb, B. P., Bitz, C. M., Lin, S.-J., and Zhang, M.: The Formulation and Atmospheric Simulation of the Community Atmosphere Model Version 3 (CAM3), J. Climate, 19, 2144-2161, doi:10.1175/JCLI3760.1, 2006b.

Cox, P. M., Betts, R. A., Jones, C. D., Spall, S. A., and Totterdell, I. J.: Acceleration of global warming due to carbon-cycle feedbacks in a coupled climate model, Nature, 408, 184-187, doi:10.1038/35041539, 2000.

Deser, C., Capotondi, A., Saravanan, R., and Phillips, A. S.: Tropical Pacific and Atlantic Climate Variability in CCSM3, J. Climate, 19, 2451-2481, doi:10.1175/JCLI3759.1, 2006.

Doney, S. C., Lima, I., Feely, R. A., Glover, D. M., Lindsay, K., Mahowald, N., Moore, J. K., and Wanninkhof, R.: Mechanisms governing interannual variability in upper-ocean inorganic carbon system and air-sea $\mathrm{CO}_{2}$ fluxes: Physical climate and atmospheric dust, Deep Sea Res. Part II: Topical Studies in Oceanography, 56, 640-655, doi:10.1016/j.dsr2.2008.12.006, 2009a.

Doney, S. C., Lima, I., Moore, J. K., Lindsay, K., Behrenfeld, M. J., Westberry, T. K., Mahowald, N., Glover, D. M., and Takahashi, T.: Skill metrics for confronting global upper ocean ecosystembiogeochemistry models against field and remote sensing data, J. Mar. Syst., 76, 95-112, doi:10.1016/j.jmarsys.2008.05.015, 2009b.

Duggen, S., Croot, P., Schacht, U., and Hoffmann, L.: Subduction zone volcanic ash can fertilize the surface ocean and stimulate phytoplankton growth: Evidence from biogeochemical experiments and satellite data, Geophys. Res. Lett., 34, L01612, doi:10.1029/2006GL027522, 2007.

Duggen, S., Olgun, N., Croot, P., Hoffmann, L., Dietze, H., Delmelle, P., and Teschner, C.: The role of airborne volcanic ash for the surface ocean biogeochemical iron-cycle: a review, Biogeosciences, 7, 827-844, doi:10.5194/bg-7-827-2010, 2010.

Emile-Geay, J., Seager, R., Cane, M. A., Cook, E. R., and Haug, G. H.: Volcanoes and ENSO over the Past Millennium, J. Climate, 21, 3134-3148, 2008.

Friedlingstein, P. and Prentice, I.: Carbon climate feedbacks: a review of model and observation based estimates, Current Opinion in Environmental Sustainability, 2, 251-257, doi:10.1016/j.cosust.2010.06.002, 2010.

Friedlingstein, P., Cox, P., Betts, R., Bopp, L., von Bloh, W., Brovkin, V., Cadule, P., Doney, S., Eby, M., Fung, I., Bala, G., John, J., Jones, C., Joos, F., Kato, T., Kawamiya, M., Knorr, W., Lindsay, K., Matthews, H. D., Raddatz, T., Rayner, P., Reick, C., Roeckner, E., Schnitzler, K.-G., Schnur, R., Strassmann, K., Weaver, A. J., Yoshikawa, C., and Zeng, N.: Climate Carbon Cycle Feedback Analysis: Results from the C4MIP Model Intercomparison, J. Climate, 19, 3337-3353, doi:10.1175/JCLI3800.1, 2006.

Frogner, P., Gíslason, S. R., and Óskarsson, N.: Fertilizing potential of volcanic ash in ocean surface water, Geology, 29, 487-490, 2001.

Frölicher, T. L., Joos, F., and Raible, C. C.: Sensitivity of atmospheric $\mathrm{CO}_{2}$ and climate to explosive volcanic eruptions, Biogeosciences, 8, 2317-2339, doi:10.5194/bg-8-2317-2011, 2011.
Grace, J., Lloyd, J., McIntyre, J., Miranda, A. C., Meir, P., Miranda, H. S., Nobre, C., Moncrieff, J., Massheder, J., Malhi, Y., Wright, I., and Gash, J.: Carbon Dioxide Uptake by an Undisturbed Tropical Rain Forest in Southwest Amazonia, 1992 to 1993, Science, 270, 778-780, doi:10.1126/science.270.5237.778, 1995.

Hansen, J., Sato, M., Ruedy, R., Lacis, A., Asamoah, K., Borenstein, S., Brown, E., Cairns, B., Caliri, G., and Campbell, M.: A Pinatubo Climate Modeling Investigation, in: The Mount Pinatubo Eruption: Effects on the Atmosphere and Climate, edited by: Fiocco, G., Fua, D., and Visconti, G., Vol. 1, 233-272, Springer-Verlag, Berlin Heidelberg, 1996.

Jones, C. D. and Cox, P. M.: Modeling the volcanic signal in the atmospheric $\mathrm{CO}_{2}$ record, Global Biogeochem. Cy., 15, 453-465, doi:10.1029/2000GB001281, 2001.

Jones, C. D., Collins, M., Cox, P. M., and Spall, S. A.: The Carbon Cycle Response to ENSO: A Coupled Climate Carbon Cycle Model Study, J. Climate, 14, 4113-4129, doi:10.1175/15200442(2001)014;4113:TCCRTE ¿2.0.CO;2, 2001.

Jones, P. D. and Kelly, P. M.: The Effect of Tropical Explosive Volcanic Eruptions on Surface Air Temperature, in: The Mount Pinatubo Eruption: Effects on the Atmosphere and Climate, edited by: Fiocco, G., Fua, D., and Visconti, G., 95-111, Springer-Verlag, Berlin Heidelberg, 1996.

Krakauer, N. Y. and Randerson, J. T.: Do volcanic eruptions enhance or diminish net primary production? Evidence from tree rings, Global Biogeochem. Cy., 17, 1118-1129, doi:10.1029/2003GB002076, 2003.

Le Quéré, C., Raupach, M. R., Canadell, J. G., and Marland et al., G.: Trends in the sources and sinks of carbon dioxide, Nat. Geosci., 2, 831-836, doi:10.1038/ngeo689, 2009.

Mahowald, N. M., Muhs, D. R., Levis, S., Rasch, P. J., Yoshioka, M., Zender, C. S., and Luo, C.: Change in atmospheric mineral aerosols in response to climate: Last glacial period, preindustrial, modern, and doubled carbon dioxide climates, J. Geophys. Res., 111, D10202, doi:10.1029/2005JD006653, 2006.

Mahowald, N. M., Lindsay, K., Rothenberg, D., Doney, S. C., Moore, J. K., Thornton, P., Randerson, J. T., and Jones, C. D.: Desert dust and anthropogenic aerosol interactions in the Community Climate System Model coupled-carbon-climate model, Biogeosciences, 8, 387-414, doi:10.5194/bg-8-387-2011, 2011.

Mass, C. F. and Portman, D. A.: Major Volcanic Eruptions and Climate: A Critical Evaluation, J. Climate, 2, 566-593, 1989.

Meehl, G. A., Washington, W. M., Santer, B. D., Collins, W. D., Arblaster, J. M., Hu, A., Lawrence, D. M., Teng, H., Buja, L. E., and Strand, W. G.: Climate Change Projections for the TwentyFirst Century and Climate Change Commitment in the CCSM3, J. Climate, 19, 2597-2616, doi:10.1175/JCLI3746.1, 2006.

Moore, J. K., Doney, S. C., and Lindsay, K.: Upper ocean ecosystem dynamics and iron cycling in a global threedimensional model, Global Biogeochem. Cy., 18, GB4028, doi:10.1029/2004GB002220, 2004.

Nemani, R. R., Keeling, C. D., Hashimoto, H., Jolly, W. M., Piper, S. C., Tucker, C. J., Myneni, R. B., and Running, S. W.: Climate-Driven Increases in Global Terrestrial Net Primary Production from 1982 to 1999, Science, 300, 1560-1563, doi:10.1126/science.1082750, 2003.

Oman, L., Robock, A., Stenchikov, G., Schmidt, G. A., and Ruedy, R.: Climatic response to high-latitude volcanic eruptions, J. Geophys. Res., 110, D13103, doi:10.1029/2004JD005487, 2005. 
Randerson, J. T., Hoffman, F. M., Thornton, P. E., Mahowald, N. M., Lindsay, K., Lee, Y.-H., Nevison, C. D., Doney, S. C., Bonan, G., Stöckli, R., Covey, C., Running, S. W., and Fung, I. Y.: Systematic Assessment of Terrestrial Biogeochemistry in Coupled Climate-Carbon Models, Global Change Biol., 15, 24622484, doi:10.1111/j.1365-2486.2009.01912.x, 2009.

Robock, A. and Liu, Y.: The Volcanic Signal in Goddard Institute for Space Studies Three-Dimensional Model Simulations, J. Climate, 7, 44-55, doi:10.1175/15200442(1994)007;0044:TVSIGI;2.0.CO;2, 1994.

Robock, A. and Mao, J.: Winter warming from large volcanic eruptions, Geophys. Res. Lett., 19, 2405-2408, doi:10.1029/92GL02627, 1992.

Robock, A. and Mao, J.: The Volcanic Signal in Surface Temperature Observations, J. Climate, 8, 1086-1103, 1995.

Sarmiento, J. L.: Atmospheric $\mathrm{CO}_{2}$ stalled, Nature, 365, 697-698, doi:10.1038/365697a0, 1993

Sarmiento, J. L., Gloor, M., Gruber, N., Beaulieu, C., Jacobson, A. R., Mikaloff Fletcher, S. E., Pacala, S., and Rodgers, K.: Trends and regional distributions of land and ocean carbon sinks, Biogeosciences, 7, 2351-2367, doi:10.5194/bg-7-23512010, 2010.

Schneider, D. P., Ammann, C. M., Otto-Bliesner, B. L., and Kaufman, D. S.: Climate response to large, highlatitude and low-latitude volcanic eruptions in the Community Climate System Model, J. Geophys. Res., 114, D15101, doi:10.1029/2008JD011222, 2009.

Shindell, D. T., Schmidt, G. A., Mann, M. E., and Falugevi, G.: Dynamic winter climate response to large tropical volcanic eruptions since 1600, J. Geophys. Res., 109, D05104, doi:10.1029/2003JD004151, 2004.

Sitch, S., Huntingford, C., Gedney, N., Levy, P. E., Lomas, M., Piao, S. L., Betts, R., Ciais, P., Cox, P., Friedlingstein, P., Jones, C. D., Prentice, I. C., and Woodward, F. I.: Evaluation of the terrestrial carbon cycle, future plant geography and climate-carbon cycle feedbacks using five Dynamic Global Vegetation Models (DGVMs), Global Change Biol., 14, 2015-2039, doi:10.1111/j.1365-2486.2008.01626.x, 2008.
Stenchikov, G., Hamilton, K., Stouffer, R. J., Robock, A., Ramaswamy, V., Santer, B., and Graf, H.-F.: Arctic Oscillation response to volcanic eruptions in the IPCC AR4 climate models, J. Geophys. Res., 111, D07107, doi:10.1029/2005JD006286, 2006.

Thornton, P. E. and Zimmermann, N. E.: An Improved Canopy Integration Scheme for a Land Surface Model with Prognostic Canopy Structure, J. Climate, 20, 3902-3923, doi:10.1175/JCLI4222.1, 2007.

Thornton, P. E., Lamarque, J.-F., Rosenbloom, N. A., and Mahowald, N. M.: Influence of carbon-nitrogen cycle coupling on land model response to $\mathrm{CO}_{2}$ fertilization and climate variability, Global Biogeochem. Cy., 21, GB4018, doi:10.1029/2006GB002868, 2007.

Thornton, P. E., Doney, S. C., Lindsay, K., Moore, J. K., Mahowald, N., Randerson, J. T., Fung, I., Lamarque, J.-F., Feddema, J. J., and Lee, Y.-H.: Carbon-nitrogen interactions regulate climate-carbon cycle feedbacks: results from an atmosphereocean general circulation model, Biogeosciences, 6, 2099-2120, doi:10.5194/bg-6-2099-2009, 2009.

Trenberth, K. E. and Dai, A.: Effects of Mount Pinatubo volcanic eruption on the hydrological cycle as an ana$\log$ of geoengineering, Geophys. Res. Lett., 34, L15702, doi:10.1029/2007GL030524, 2007.

Watson, A. J.: Volcanic iron, $\mathrm{CO}_{2}$, ocean productivity and climate, Nature, 385, 587-588, doi:10.1038/385587b0, 1997.

Welp, L. R., Keeling, R. F., Meijer, H. A. J., Bollenbacher, A. F., Piper, S. C., Yoshimura, K., Francey, R. J., Allison, C. E., and Wahlen, M.: Interannual variability in the oxygen isotopes of atmospheric $\mathrm{CO}_{2}$ driven by El Nino, Nature, 477, 579-582, doi:10.1038/nature10421, 2011.

Yeager, S. G., Shields, C. A., Large, W. G., and Hack, J. J.: The Low-Resolution CCSM3, J. Climate, 19, 2545-2566, doi:10.1175/JCLI3744.1, 2006.

Zender, C. S., Bian, H., and Newman, D.: Mineral Dust Entrainment and Deposition (DEAD) model: Description and 1990s dust climatology, J. Geophys. Res., 108, 4416, doi:10.1029/2002JD002775, 2003. 